\title{
PELATIHAN PEMANFAATAN MEDIA PEMBELAJARAN LINKTREE DAN MICROSOFT KAIZALA UNTUK MENUNJANG PEMBELAJARAN DARING BAGI GURU
}

\author{
Farida Fitriani1), Muzakkir'1), Endah Resnandari Puji Astuti1), Agus Jayadi1), Sony Gunawan2), \\ 1)Program Studi Teknologi Pendidikan, Fakultas Ilmu Pendidikan dan Psikologi, Universitas Pendidikan Mandalika, \\ Mataram, NTB, Indonesia \\ 2)Program Studi Bimbingan dan Konseling, Fakultas IImu Pendidikan dan Psikologi, Universitas Pendidikan Mandalika, \\ Mataram, NTB, Indonesia \\ Corresponding author: Muzakkir \\ E-mail : farida.fitriani@undikma.ac.id
}

Diterima 27 Juli 2021, Direvisi 01 Agustus 2021, Disetujui 02 Agustus 2021

\begin{abstract}
ABSTRAK
Tujuan pelatihan ini adalah meningkatkan pemahaman dan kemampuan guru dalam melaksanakan pembelajaran daring yang mudah dan efisien dengan menggunakan media Linktree dan Microsoft Kaizala untuk menunjang pembelajaran daring. Metode yang akan digunakan dalam pelaksanaan program pengabdian ini yakni pelatihan pemanfaatan media pembelajaran secara partisipatif dengan tahapan persiapan, pelaksanaan, dan evaluasi. Adapun teknik pelaksanaan program ini akan dilakukan secara tim. Tim dosen tersebut ditugaskan untuk mendampingi guru-guru agar pelaksanaan pelatihan agar berjalan secara optimal. Program ini dilaksanakan di SMPN 12 Mataram dengan seluruh guru. Adapun hasil pengabdian pelatihan pemanfaatan media pembelajaran sebagai berikut (1) Guru aktif mengikuti proses pelaksanaan program pelatihan tersebut, (2) Guru memiliki pemahaman dan kemampuan untuk menggunakan dan memanfaatkan media pembelajaran, (3) Peningkatan inovasi dan kreativitas guru dalam mengajar dengan memanfaatkan media pembelajaran yang efektif dan efisien.
\end{abstract}

Kata kunci: daring; linktree; media pembelajaran; microsoft kaizala

\begin{abstract}
The purpose of this training is to improve the understanding and ability of teacher to carrying out easy and efficient online learning by using Linktree and Microsoft Kaizala media to support online learning. The method that will be used in this program is training in the use of leaning media in a participatory with the stages of preparation, implementation, and evaluation. The technique for implementation this program is will be carried out in a team. The team is lecturers assigned to assist the teachers so that the training implementation runs optimally. This program will be implementation at SMPN 12 Mataram with all teachers. The results of this program are (1) teachers actively participate in the process of implementing the training program, (2) the teachers have understanding and ability to use and utilize learning media, and (3) increasing teachers innovation and creativity in teaching by utilizing effective and efficient leaning media.
\end{abstract}

Keywords: linktree; in the network; intructional media; microsoft kaizala

\section{PENDAHULUAN}

Perkembangan dan kemajuan teknologi berpengaruh langsung terhadap dunia pendidikan lebih khusus tergesernya paradigma interaksi antara guru dan siswa. Pengaruh ini semakin menuntut kemampuan guru dalam berinovasi serta kreatif untuk memanfaat teknologi yang ada. Kreativitas guru akan sangat menentukan mutu dan kualitas proses pembelajaran, jika daya dukung unsur pembelajaran baik maka prosesnya akan baik pula, bahkan outputnyapun akan lebih berkualitas dan bisa saja berdampak langsung terhadap hasil belajar yang diperoleh siswa.
Proses pembelajaran umumnya di tafsirkan sebagai salah satu interaksi yang membutuhkan satu sama lain, baik itu antara penyampai pesan dan penerima yang bersifat umum maupun antara guru dan siswa. Dalam hal ini guru berfungsi sebagai sumber pesan yang menyampaikan pesan berupa materi pelajaran yang akan diterima oleh siswa sebagai penerimanya demi mencapai tujuan pembelajaran yang sudah ditentukan, sehingga tujuan pembelajaran tersebut dapat tercapai lebih optimal, maka guru harus dapat menyiasati supaya semua komponen dalam sistem pembelajaran seperti materi, metode, peserta didik, media pembelajaran, evaluasi 
dan lingkungan belajar dapat berperan secara maksimal, sehingga terjadi komunikasi antara guru dan siswa yang saling menguntungkan.

$$
\text { Kaitan dengan komponen }
$$

pembelajaran tersebut ada salah satu unsur terpenting yakni media pembelajaran. Media Pembelajaran dapat diartikan sebagai sesuatu yang mengantarkan pesan pembelajaran antara pemberi pesan kepada penerima pesan (Anitah, 2012). Demikian juga dikatakan Arsyad, (2009) setiap sistem pembelajaran yang melakukan peran mediasi, mulai dari guru sampai kepada peralatan paling canggih disebut media. Adapun fungsi pokok media pembelajaran yaitu sebagai alat bantu mewujudkan situasi belajar mengajar yang efektif untuk mempertinggi mutu belajar mengajar (Sumiharsono et al., 2017). Media pembelajaran sebagai salah satu sumber belajar memiliki peranan yang sangat penting karena tidak hanya sekedar sebagai alat bantu mengajar, tetapi sebagai satu kesatuan yang tidak terpisahkan (integral) dalam proses pembelajaran. Terlebih dimasa covid-19 ini tentunya guru lebih kreatif dalam memanfaatkan media pembelajaran online. Selain itu, banyak guru yang kesulitan untuk menyampaikan materi pembelajaran. Berdasarkan observasi guru SMPN 12 Mataram melakukan pembelajaran daring melalui WhatsApp. WhatsApp memiliki fitur-fitur yang terbatas (Daheri et al., 2020), sehingga guru dan peserta didik tidak maksimal melakukan proses belajar mengajar. Oleh karena itu, tim akan melakukan pelatihan tentang penggunaan media Linktree dan Microsoft Kaizala salah satu media yang sangat mudah dan interaktif yang mendukung pembelajaran daring.

Media pembelajaran Linktree merupakan salah satu media berbasis website yang fungsi utamanya adalah untuk mendukung pembelajaran jarak jauh, seperti embed materi, quiz, prensensi dan sebagainya, yang disediakan secara gratis sehingga memudahkan penggunanya lebih mudah untuk melaksanakan pembelajaran secara online. Sedangkan Microsoft Kaizala adalah aplikasi pesan aman dan manajemen kerja yang memungkinkan siswa untuk berkolaborasi dengan orang lain. Microsoft Kaizala juga dapat mengirim dan menerima pesan instan, mengkoordinasikan tugas, mengirimkan faktur, dan menggunakan alat khusus untuk berinteraksi dengan peserta didik di mana pun berada. Microsoft Kaizala yang dihadirkan sebagai solusi berdasarkan pertimbangan dari aplikasi yang mudah digunakan (Balkist et al., 2021)
Media Linktree dan Microsoft Kaizala digunakan sebagai media pembelajaran online yang sangat mudah diorientasikan meskipun masih pemula. Sehingga memungkinkan bagi guru untuk memanfaatkan media dengan mudah. Karena sebagian besar guru yang ada di sekolah tersebut belum mamahami pemanfaatan media pembelajaran daring, khususnya media pembelajaran Linktree dan Microsoft Kaizala sebagai media pembelajaran jarak jauh, meskipun sarana pendukung sudah memadai. Dengan demikian, tim pengabdian ingin mengadakan pelatihan pemanfaatan media pembelajaran Linktree dan Microsoft Kaizala untuk guru-guru, sehingga nantinya dapat mendukung proses pembelajaran yang lebih baik. Tujuannya yakni untuk meningkatkan kamampuan guru dan menciptakan inovasi dan kreativitas mengajar dengan memanfaatkan media pembelajaran Linktree dan Microsoft Kaizala serta adanya dukungan sarana yang sudah ada disekolah tersebut, baik itu berupa internet, handphone, leptop/komputer yang dimiliki oleh guru dan sekolah tersebut.

Berdasarkan hal tersebut guru dituntut kreatif dalam memanfaatkan teknologi terutama dalam memanfatkan media pembelajaran yang mendukung pembelajaran daring (dalam jaringan), sedangkan kondisi guru belum dapat maksimal memanfaatkan media pembelajaran daring seperti Linktree dan Microsoft Kaizala. Persoalan tersebut penting untuk diberi pelatihan dalam pemanfaatan media yang dimaksud, salah satunya melalui program pengabdian kepada masyarakat.

\section{METODE}

Pelatihan ini dilaksanakan di SMPN 12 Mataram dengan seluruh guru mata pelajaran dengan jumlah 30 . Metode pelaksanaan program pengabdian masyarakat ini akan dilakukan secara terpadu dan partisipatif dengan tahapan persiapan, pelaksanaan dan evaluasi.

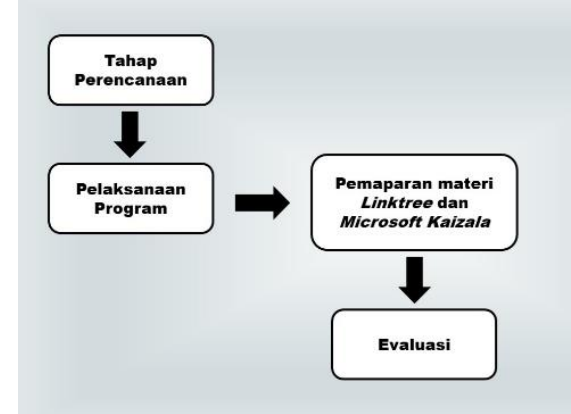

Gambar 1: Alur Tahapan Pelaksanaan
Program

1. Tahap persiapan, pada tahap ini tim melakukan observasi (analisis kebutuhan 
program berdasarkan permasalahan guru) dan mengurus izin pelaksanaan pelatihan pada kepala sekolah. Dalam tahap persiapan, tim dosen bekerja mulai dari observasi awal untuk mengetahui kondisi sekolah, kemudian dilakukan evaluasi agar dapat dipetakan kebutuhan protitas dan kegiatan berjalan dengan maksimal.

2. Tahap pelaksanaan. Pada tahap ini, narasumber beserta tim melalukan pemaparan materi dan praktik serta bimbingan atau pendampingan secara intensif kepada guru yang menjadi peserta pelatihan.

3. Tahap evaluasi kegiatan pengabdian yang telah dilaksanakan.

Indikator ketercapaian PKM ini adalah $80 \%$ guru dapat memahami dan dapat mengoprasikan media pembelajaran Linktree dan Microsoft Kaizala. Pada akhir pengabdian, diadakan evaluasi dan refleksi kegiatan. Evaluasi adalah kegiatan yang dilakukan untuk melihat ketercapaian target yang telah di rencanakan (Ngurah \& Handayana, 2019) Evaluasi pengabdian ini dengan membuat laporan kegiatan dengan mengakumulasikan, menganalisis dan mendeskripsikan kegiatan dan data selama pelatihan berlangsung.

\section{HASIL DAN PEMBAHASAN}

Pengabdian kepada masyarakat ini telah dilaksanakan pada tanggal 5 Juni 2021 bertempat di SMPN 12 Mataram, Jalan Ahmad Yani, Kecamatan Selagalas. Kegiatan dihadiri oleh seluruh guru bidang studi SMP 12 Mataram. Kegiatan pelatihan ini, tim membagi menjadi 3 tahap yaitu, (1) perencanaan, (2) pelaksanaan, (3) evaluasi dan refleksi. Adapun penjelasan setiap tahap adalah sebagai berikut.

\section{Tahap perencanaan}

Tahap perencanaa kegiatan program pengabdian berjalan lancar. Beberapa fakta hasil observasi dan wawancara di lapangan tentang penggunaan media pembelajaran pada guru masih sangat terbatas yaitu melalui WhatsApp. WhatsApp menjadi salah satu aplikasi yang paling sering digunakan oleh pendidik dan peserta didik dalam melakukan proses pembelajaran jarak jauh. Hal ini dikarenakan, WhatsApp mudah digunakan dan sudah menjadi familiar di masyarakat. Namun, dibalik semua itu, WhatsApp tidak dapat dijadikan satusatunya aplikasi untuk menjunjang pembelajaran jarak jauh. Mengingat masih terbatasnya forum untuk pertemuan virtual. Daheri et al., (2020) mengatakan penggunaan WhatsApp dalam pembelajaran kurang efektif, karena Ketika menerapkan pembelajaran daring pendidik tidak dapat mengontrol secara langsung, partisipasi dan aktifitas peserta didik. Dengan adanya permasalahan tersebut, tim membuat kesepakatan dan meminta izin kepada kepala sekolah untuk membuat pelatihan pemanfaatan media pembelajaran Linktree dan Microsoft Kaizala untuk menunjang pembelajaran daring bagi guru.

Setelah observasi dilaksanakan dan tim membuat kesepakatan dan kerjasama kepada pihak sekolah, kemudian tim menentukan 2 narasumber terkait penyampaian materi media pembelajaran Linktree dan Microsoft Kaizala. Narasumber dimaksud adalah Dosen Fakultas IImu Pendidikan dan Psikologi yaitu program studi Teknologi Pendidikan Bernama Muzzakir, M.Pd. dan Endah Resnandari P.A. M.Pd.

\section{Tahap Pelaksanaan}

Sesuai dengan tujuan pengabdian ini yaitu meningkatkan pemahaman dan kemampuan guru dalam melaksanakan pembelajaran daring yang mudah dan efisien dengan menggunakan media Linktree dan Microsoft Kaizala. melalui kegiatan ini, akan membuka wawasan guru tentang banyak aplikasi yang dapat digunakan untuk pembelajaran. Pada tahap pelaksanaan, tim melakukan beberapa sesi yaitu: (1) pembukaan, (2) pemaparan materi, (4) Praktik / latihan disertai bimbingan dan pendampingan oleh tim, (4) tanya jawab. Berikut penjelasan disetiap sesi. (1) Pada sesi pembukaan, kegiatan pelatihan ini dibuka oleh kepala sekolah SMPN 12 Mataram dan dihadiri oleh 30 guru bidang studi dengan sangat antusias. (2) Sesi pemaparan materi Linktree dan Microsoft Kaizala yang dipersentasikan oleh narasumber secara bergilir. (3) Praktik / latihan diberikan kepada guru atau peserta untuk mengoprasikan Linktree dan Microsoft Kaizala serta dibimbing dari proses pengunduhan dan pengaplikasiannya. Dari segi latihan ini dapat disimpulkan bahwa guru sangat antusias mengikuti pelatihan media pembelajaran Linktree dan Microsoft Kaizala untuk menunjang pembelajaran di kelas, hal tersebut dapat dilihat dari sesi tanya jawab. (4) Tanya jawab pada sesi ini, tim memberikan kesempatan kepada guru untuk bertanya langsung kepada narasumber atau tim pengabdian terkait dengan materi yang dipaparkan. Hal ini bertujuan agar guru benar-benar memahami 
dan mampu mengaplikasikan media dalam pembelajaran. Dengan begitu, guru dapat mencipatakan suasana dan proses pembelajaran yang menarik dan efektif agar peserta didik menjadi termotivasi dan berkembang.

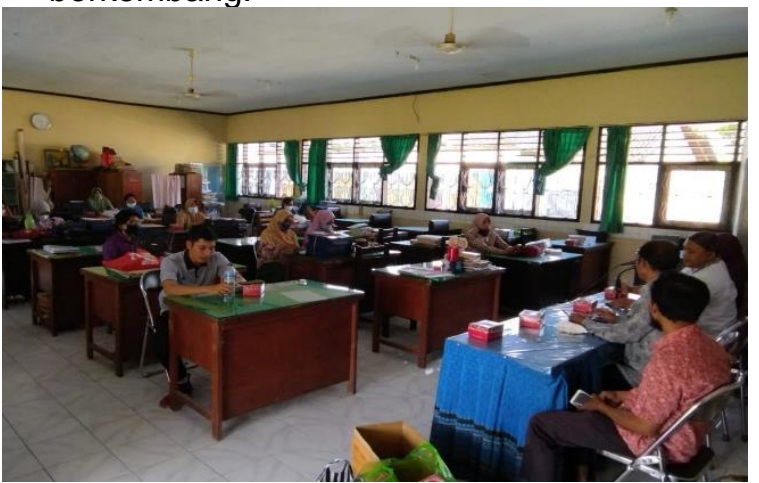

Gambar 2: Pelaksanaan kegiatan

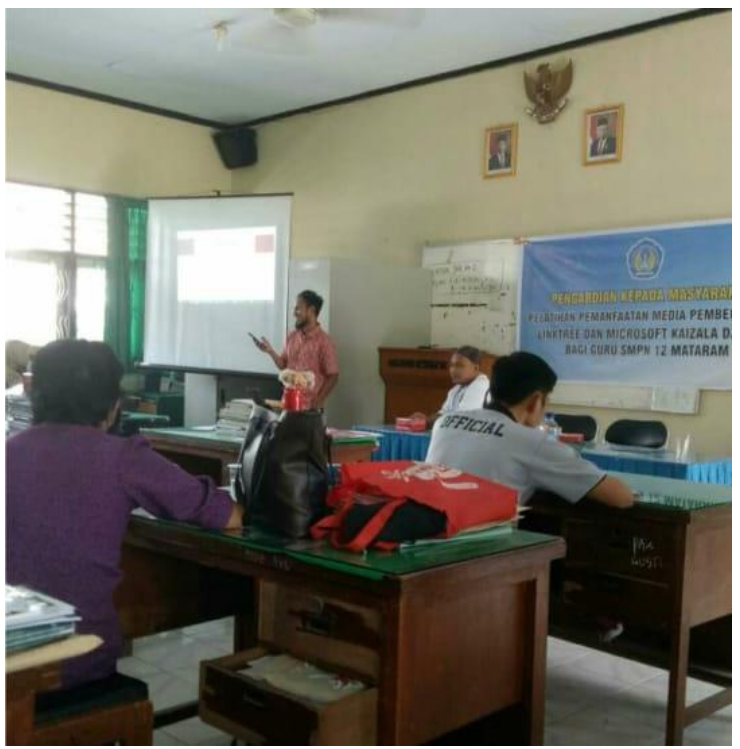

Gambar 3: Pemaparan Materi oleh Narasumber

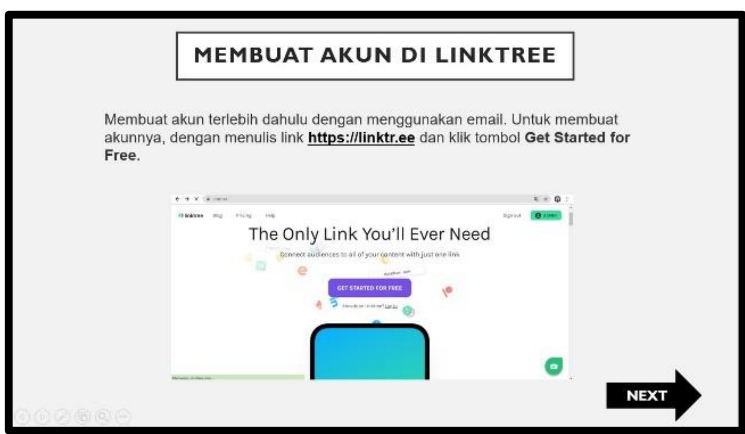

Gambar 4: Materi pembuatan akun Linktree
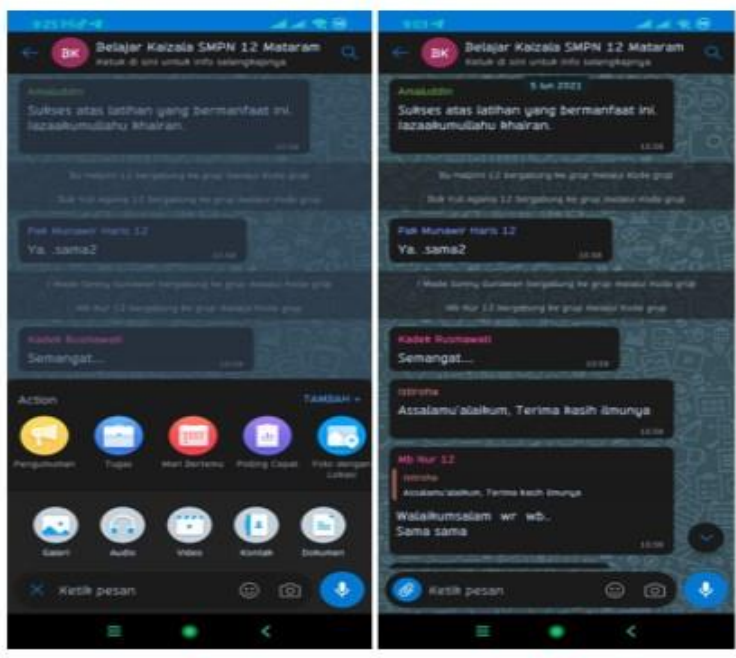

Gambar 5: Praktik Pembuatan kelas di Microsoft Kaizala

3. Evaluasi dan refleksi.

Evaluasi merupakan suatu proses menyediakan informasi yang dapat dijadikan sebagai pertimbangan untuk menentukan harga dan jasa dari tujuan yang dicapai, desain, implementasi dan dampak untuk membantu membuat keputusan, membantu pertanggungjawaban dan meningkatkan pemahaman terhadap fenomena (Widoyoko, 2012). Refleksi pada pelatihan ini mempunyai tujuan yaitu untuk melihat respon peserta dalam sebuah pelatihan atau penyampaian sebuah materi dari narasumber, agar tim dapat memahami kelemahan dan kekurangan dari pelatihan ini. Hal ini sangat bermanfaat untuk tim agar dikemudian hari dapat memberikan pelatihan yang efektif di kesempatan lainnya. Selanjutnya evaluasi dilakukan untuk mengetahui tingkat penguasaan atau pemahaman peserta terhadap pelatihan yang telah dilakukan. Evaluasi keberhasilan kegiatan pelatihan ini dilakukan setelah semua sesi dilaksanakan pada akhir kegiatan. Keberhasilan kegiatan ini dilihat dari respon positif para peserta melalui evaluasi yang diberikan serta diskusi yang dilakukan selama kegiatan. Evaluasi kegiatan juga dilakukan berupa kuesioner yang diisi peserta pelatihan. Melalui pelatihan ini, diharapkan guru dapat memanfaatkan dan menerapkan media pembelajaran tersebut agar peserta didik dapat kreatif memanfaatkan media pembelajaran dan mempermudah guru untuk memantau keaktifan siswa dalam pembelajaran jarak jauh.

\section{SIMPULAN}

Pelatihan pemanfaatan media pembelajaran Linktree dan Microsoft Kaizala 
untuk menunjang pembelajaran daring bagi guru berjalan dengan sangat baik. Peserta atau para guru SMPN 12 Mataram mengetahui manfaat media pembelajaran Linktree dan Microsoft Kaizala dalam proses pembelajaran yang tidak terpaku pada WhatsApp. Peserta dapat memanfaakan fitur-fitur yang disediakan sebagai media pembelajaran untuk mengontrol kelas dan mempermudah proses belajar mengajar. Seluruh peserta sepakat bahwa Linktree dan Microsoft Kaizala dapat membantu proses belajar mengajar dan mengenalkan kepada peserta didik.

\section{UCAPAN TERIMA KASIH}

Tim mengucapkan terima kasih yang sebesar-besarnya pada LPPM Universitas Pendidikan Mandalika yang telah membiayai PKM Pelatihan Pemanfaatan Media Pembelajaran Linktree dan Microsoft Kaizala untuk Menunjang Pembelajaran Daring bagi Guru di SMPN 12 Mataram.

\section{DAFTAR RUJUKAN}

Anitah, S. (2012). Media Pembelajaran. Yumna Pustaka.

Arsyad, A. (2009). Media Pembelajaran. RajaGrafindo Persada.

Balkist, P. S., Nurcahyono, N. A., Lukman, H. S., Setiani, A., Agustiani, N., Mulyanti, Y., \& Imswatama, A. (2021). Pelatihan Penggunaan Microsoft Kaizala Sebagai Media Pembelajaran Daring Matematika Di Era New Normal. JMM (Jurnal Masyarakat Mandiri), 5(Vol 5, No 1 (2021): Februari), $\quad$ 55-64. http://journal.ummat.ac.id/index.php/jmm/ article/downloadSuppFile/3235/772

Daheri, M., Juliana, J., Deriwanto, D., \& Amda, A. D. (2020). Efektifitas WhatsApp sebagai Media Belajar Daring. Jurnal Basicedu, 4(4), 775-783. https://doi.org/10.31004/basicedu.v4i4.44 5

Ngurah, I. G., \& Handayana, Y. (2019). PROGRAM STUDI FISIKA FMIPA UNIVERSITAS MATARAM sesuai dengan konsep. 2, 37-41.

Sumiharsono, R., Hasanah, H., Ariyanto, D., \& Abadi, P. (2017). Media Pembelajaran: Buku Bacaan Wajib Dosen, Guru dan Calon Pendidik. Pustaka Abadi. https://books.google.co.id/books?id=VJtl DWAAQBAJ

Widoyoko, E. P. (2012). Evaluasi Program Pembelajaran Panduan Praktis Bagi Pendidik dan Calon Pendidik. Pustaka Pelajar. 